\title{
Diagnosis and management of wide complex tachycardia in the emergency department
}

\author{
James-Jules Linton $^{1} \cdot$ Debra Eagles $^{2,3} \cdot$ Martin S. Green $^{4} \cdot$ Steven Alchi ${ }^{1} \cdot$ Marie-Joe Nemnom $^{5} \cdot$ Ian G. Stiell ${ }^{2,3,6}$ (1)
}

Received: 26 July 2021 / Accepted: 24 November 2021 / Published online: 23 January 2022

(C) The Author(s), under exclusive licence to Canadian Association of Emergency Physicians (CAEP)/ Association Canadienne de Médecine d'Urgence (ACMU) 2022

\begin{abstract}
Introduction While wide complex tachycardia (WCT) is potentially lethal, little is known about its incidence in the ED or about expertise of ED physicians in diagnosing and treating it. We sought to compare WCT ED cases that were primary arrhythmias versus those with rapid heart rate secondary to medical issues, as well as the accuracy of ED diagnosis and appropriateness of treatment.

Methods We conducted a health records review at a large academic hospital ED staffed by 95 physicians and included consecutive patients over 28 months (2018-2020) with WCT (heart rate $\geq 120 \mathrm{bpm}$ and QRS $\geq 120 \mathrm{~ms}$ ). Cases were adjudicated for the accuracy of ECG diagnosis versus the cardiology read and for correctness of treatment as per guidelines by two ED physicians and one cardiologist.

Results We identified 306 eligible cases ( $0.2 \%$ of all ED visits): mean age 73.9 years, male $66.0 \%$, admitted $53.3 \%$, died in ED 2.3\%. Primary arrhythmias and secondary tachycardias were each 50.0\% (95\% CI 44.4-55.6\%). ED physicians correctly interpreted $81.2 \%$ of ECGs. The most common presenting arrythmias and \% correct were: atrial fibrillation $42.7 \%(95.0 \%)$, atrial flutter $22.2 \%$ (63.5\%), sinus tachycardia 12.0\% (78.6\%), and supraventricular tachycardia (SVT) $11.1 \%(68.0 \%)$. Treatments were judged optimal in $84.3 \%$ of primary WCT and $86.9 \%$ in secondary WCT. Treatments were suboptimal for: inappropriate drug (3.9\% for primary versus $1.3 \%$ for secondary), failure to reduce heart rate $<100$ prior to discharge home (9.1\% for primary versus $34.4 \%$ for secondary), and not treating the underlying cause in $5.9 \%$ of secondary WCT.

Conclusions WCT cases were evenly split between primary arrhythmias and secondary cases. ED physicians interpreted the ECG correctly in $81 \%$ but over-called atrial flutter and SVT. They implemented appropriate care in most cases but sometimes failed to adequately control heart rate or to treat the underlying condition, suggesting opportunities to improve care of WCT in the ED.
\end{abstract}

Keywords Emergency department · Arrhythmia · Wide QRS complex

Ian G. Stiell

istiell@ohri.ca

1 Faculty of Medicine, University of Ottawa, Ottawa, ON, Canada

2 Department of Emergency Medicine, University of Ottawa, Ottawa, Ontario, ON, Canada

3 Ottawa Hospital Research Institute, Ottawa, ON, Canada

4 Division of Cardiology, University of Ottawa Heart Institute, Ottawa, ON, Canada

5 Clinical Epidemiology Program, Ottawa Hospital Research Institute, Ottawa, ON, Canada

6 Clinical Epidemiology Unit, F657, The Ottawa Hospital, 1053 Carling Avenue, Ottawa, ON K1Y 4E9, Canada 


\section{Résumé}

Introduction Bien que la tachycardie à complexe large (wide complex tachycardia WCT) soit potentiellement mortelle, on sait peu de choses sur son incidence aux urgences ou sur l'expertise des médecins des urgences en matière de diagnostic et de traitement. Nous avons cherché à comparer les cas WCT aux urgences qui étaient des arythmies primaires par rapport à ceux avec une fréquence cardiaque rapide secondaire à des problèmes médicaux, ainsi que la précision du diagnostic des urgences et la pertinence du traitement.

Méthodes Nous avons effectué un examen des dossiers médicaux dans les urgences d'un grand hôpital universitaire où travaillent 95 médecins et avons inclus des patients consécutifs sur 28 mois (2018-2020) présentant un WCT (fréquence cardiaque $\geq 120 \mathrm{bpm}$ et QRS $\geq 120 \mathrm{~ms}$ ). Les cas ont été jugés par deux médecins des urgences et un cardiologue pour l'exactitude du diagnostic ECG par rapport à la lecture cardiologique et pour l'exactitude du traitement conformément aux directives.

Résultats Nous avons identifié 306 cas éligibles $(0,2 \%$ de toutes les visites aux urgences) : âge moyen 73,9 ans, hommes $66,0 \%$, admis $53,3 \%$, décédés aux urgences $2,3 \%$. Les arythmies primaires et les tachycardies secondaires étaient chacune de 50,0 \% (IC $95 \%$ 44,4-55,6\%). Les médecins des urgences ont interprété correctement 81,2\% des ECG. Les arythmies les plus fréquentes et les pourcentages d'interprétation correcte étaient les suivants : fibrillation auriculaire 42,7 \% (95,0 $\%$ ), flutter auriculaire $22,2 \%(63,5 \%)$, tachycardie sinusale $12,0 \%(78,6 \%)$ et tachycardie supraventriculaire (TSV) 11,1 $\%(68,0 \%)$. Les traitements ont été jugés optimaux dans 84,3\% des WCT primaires et 86,9\% des WCT secondaires. Les traitements étaient sous-optimaux pour les raisons suivantes : médicament inapproprié (3,9\% pour le primaire contre 1,3\% pour le secondaire), incapacité à réduire la fréquence $<100$ avant le retour à domicile $(9,1 \%$ pour le primaire contre $34,4 \%$ pour le secondaire) et absence de traitement de la cause sous-jacente dans 5,9\% du WCT secondaire.

Conclusions Les cas de WCT étaient répartis uniformément entre les arythmies primaires et les cas secondaires. Les médecins du service d'urgence ont correctement interprété l'ECG dans $81 \%$ des cas, mais ont surévalué le flutter auriculaire et la TSV. Ils ont mis en œuvre des soins appropriés dans la plupart des cas, mais n'ont pas toujours réussi à contrôler adéquatement la fréquence cardiaque ou à traiter la maladie sous-jacente, ce qui laisse entrevoir des possibilités d'améliorer les soins de WCT au service d'urgence.

\section{Clinician's capsule}

\section{What is known about the topic?}

While wide complex tachycardia (WCT) is potentially lethal, little is known about the expertise of ED physicians in its management.

\section{What did this study ask?}

This academic ED health records review evaluated 306 consecutive patients with WCT (heart rate $\geq 120 \mathrm{bpm}$ and $\mathrm{QRS} \geq 120 \mathrm{~ms}$ ).

\section{What did this study find?}

There were equal numbers of primary and secondary arrhythmias; physicians interpreted $82 \%$ of ECGs correctly and sometimes failed to deliver appropriate care.

\section{Why does this study matter to clinicians?}

There are opportunities to improve ED management of WCT including controlling heart rate and treating the underlying medical condition.

\section{Introduction}

Wide QRS complex tachycardia (WCT), defined as a heart rate greater than 100 beats per minute accompanied by a widened QRS complex ( $\geq 120 \mathrm{~ms}$ ), is an uncommon but potentially lethal arrhythmia treated in the emergency department (ED) [1-3]. Some cases are benign and are due to sinus tachycardia with aberrancy, while others are more serious and are due to ventricular tachycardia (VT) or ventricular pre-excitation syndromes. Other cases of WCT are accelerated ventricular response due to electrolyte imbalances, sepsis, drug toxicity, and many other medical conditions [1-3]. Distinguishing between the types of WCT may be difficult yet must be done rapidly to determine the correct treatment $[2,3]$.

The accurate diagnosis of WCT and identification of its etiology is complicated by the difficulty of rapidly interpreting electrocardiograms (ECGs) in an unwell patient. Several algorithms for WCT ECG interpretation exist; however, despite these tools, there continues to be misidentification of the underlying mechanism based on the initial ECG analysis in the ED [2-6]. Current approaches to management of WCT are outlined in the Advanced Cardiac Life Support (ACLS) guidelines [7]. The ACLS guidelines provide an algorithm for treating WCT, with the first step being the determination of hemodynamic stability; unstable patients presenting with WCT should receive immediate cardioversion. Depending on the etiology of the WCT, several treatment options exist for stable patients [6-9]. To our knowledge, there exists very little literature on the accuracy of WCT diagnosis and the appropriateness of its management in the ED. We hypothesize that there is some inaccuracy in the diagnosis of WCT for patients presenting to the ED with this arrhythmia. Further, we believe there to be considerable variation in the 
approach to management, due to the complexity of diagnosis and limited evidence base to guide clinical practice.

The overall goal of this study was to better understand the burden of disease presented by WCT and identify opportunities for improved care in the ED. Specifically, we sought to determine the incidence and etiology of WCT requiring management in a large academic hospital ED, as well as the disposition and outcomes of these cases. We wished to evaluate the accuracy of diagnosis of underlying etiology by ED physicians and to examine the variation and appropriateness of management.

\section{Methods}

\section{Design and setting}

This was a health records review of patients who presented with WCT to one ED of a tertiary care academic hospital over a 28-month period in 2018-2020. The Ottawa Hospital has 1200 beds and is in Ottawa, Ontario, Canada. The two EDs are staffed by 95 certified attending physicians and has 160,000 mostly adult visits per year. The University of Ottawa Department of Emergency Medicine has 55 residents and 20 fellows in research, education, ultrasound, simulation, and prehospital and transport medicine programs. The University of Ottawa Heart Institute is adjacent to the Civic Campus ED and is a major cardiovascular centre.

\section{Participants}

We enrolled consecutive visits of patients aged 18 years or older with evidence of a QRS complex $\geq 120 \mathrm{~ms}$ on their initial ECG in the ED as well as a heart rate $\geq 120 \mathrm{bpm}$. These cases were identified by search of the Heart Institute ECG database. We chose a cut-off of $120 \mathrm{bpm}$ to focus on more challenging cases and to exclude the large number of patients with sinus tachycardia and bundle branch block. If multiple ECGs were completed during the same ED visit, only the first ECG showing WCT was used. We were particularly interested in documenting ED management practices over the entire 28-month study period and, therefore, did not exclude subsequent ED visits. The first ED visit during the study period was designated as the index visit. We obtained approval from the Ottawa Health Science Network Research Ethics Board.

\section{Measures and data collection}

We followed most aspects of the RECORD statement for studies of routinely collected health data [10]. The sources of data were the ED health record (including triage, nursing, and physician notes), hospital electronic records (clinical, laboratory, imaging, and death certificate), clinic records, and ECG database. The latter has been maintained by the cardiology department for many years and includes all ECGs performed throughout the institution. It is searchable by multiple parameters. The following information was collected from each patient's medical chart: demographic and medical history data; ED treatments administered; adverse events; final ED diagnosis as a primary arrhythmia or increased heart rate secondary to another medical cause; and disposition and clinical outcomes. The ED physician's interpretation was obtained from the dedicated ECG interpretation line on paper charts prior to the adoption of the electronic medical record (EMR), or from the clearly recorded and time-stamped interpretation on the EMR (Epic Systems Corporation). All potential cases and medical records were reviewed by the first reviewers (J.L., S.A.) and further reviewed by a staff physician (I.G.S. or D.E.). Rather than measuring agreement we sought consensus.

Primary arrhythmia was defined as any atrial, supraventricular, or ventricular rhythm, excluding permanent AF [8]. Secondary WCT was defined as a rapid rate associated with an underlying medical condition or acute reversible precipitant (e.g. infection, acute respiratory or cardiac pathology). The differentiation of a primary arrhythmia versus secondary to a medical cause was based upon review of the clinical picture, cardiology consults, discharge summaries, review of prior ECGs, and discussion amongst two emergency physicians and one cardiac electrophysiologist (M.S.G.). Similar sources and discussions were used to determine the ED physician accuracy of clinical diagnosis and appropriateness of treatment.

Appropriateness of treatment was judged by the senior authors based on their clinical experience and standard guidelines $[7,8,11]$. We classified suboptimal treatment as: inappropriate drug or dose, failure to reduce heart rate below $100 \mathrm{bpm}$ for patients discharged from the ED [12, 13], ACLS guidelines not followed for VT, failure to cardiovert AF/AFL as indicated by Canadian guidelines [14], oral anticoagulants not prescribed when indicated by Canadian guidelines [15], and failure to treat underlying medical cause.

\section{Sample size and data analysis}

Based on initial review of the ECG database, we expected to enroll 300 eligible cases from the 28 -month period. Analysis employed descriptive statistics appropriate for continuous, ordinal, and categorical outcomes. 
Table 1 Baseline characteristics of 306 emergency department patients with rapid heart rate and wide QRS complexes

\begin{tabular}{|c|c|c|c|}
\hline Characteristics & $\begin{array}{l}\text { Primary WCT } \\
N=153\end{array}$ & $\begin{array}{l}\text { WCT secondary to } \\
\text { underlying cause } \\
N=153\end{array}$ & $\begin{array}{l}\text { Total } \\
\text { visits } \\
(N=306)\end{array}$ \\
\hline Age in years, mean & 72.5 & 75.4 & 73.9 \\
\hline Range & $19-102$ & $35-99$ & $19-102$ \\
\hline Male, $\%$ & 68.6 & 63.4 & 66.0 \\
\hline \multicolumn{4}{|l|}{ Initial vital signs, mean } \\
\hline Heart rate, bpm, $(N=152: 150: 302)^{\mathrm{a}}$ & 135.2 & 127.5 & 131.4 \\
\hline Systolic blood pressure $(\mathrm{mmHg})(N=150: 148: 298)$ & 120.6 & 128.6 & 124.6 \\
\hline Temperature $\geq 38.0{ }^{\circ} \mathrm{C}, \%(N=139: 141: 280)$ & 0.7 & 9.2 & 6.7 \\
\hline Hours from onset, mean $(\mathrm{N}=121: 98: 219)$ & 13.3 & 18.8 & 15.7 \\
\hline Time of onset uncertain, $\%$ & 20.9 & 36.0 & 28.4 \\
\hline \multicolumn{4}{|l|}{ Main presenting complaint, $\%$} \\
\hline Palpitations & 53.6 & 5.2 & 29.4 \\
\hline Shortness of breath & 8.5 & 32.0 & 20.3 \\
\hline Chest pain & 19.6 & 10.5 & 15.0 \\
\hline Weakness & 4.5 & 6.5 & 5.6 \\
\hline Cardiac arrest & 1.3 & 7.2 & 4.3 \\
\hline Ventricular fibrillation & 0.0 & 2.0 & 1.0 \\
\hline Pulseless ventricular tachycardia & 1.3 & 2.0 & 1.6 \\
\hline Pulseless electrical activity & 0.7 & 2.0 & 1.3 \\
\hline Fever & 1.3 & 3.3 & 2.3 \\
\hline ICD shock & 2.6 & 0.0 & 1.3 \\
\hline Other & 8.5 & 34.0 & 21.2 \\
\hline \multicolumn{4}{|l|}{ Acuity, $\%$} \\
\hline CTAS score $<2(N=148: 150: 298)$ & 7.4 & 22.7 & 15.1 \\
\hline GCS score $<15(N=142: 139: 281)$ & 7.8 & 38.9 & 23.1 \\
\hline \multicolumn{4}{|l|}{ Unstable vital signs, $\%$} \\
\hline Hypotensive SBP $<90$ & 15.0 & 15.0 & 15.0 \\
\hline Pulseless on arrival & 0.7 & 2.0 & 1.3 \\
\hline Pulseless after arrival & 3.3 & 3.3 & 3.3 \\
\hline Arrival by ambulance, $\%$ & 32.7 & 62.1 & 49.0 \\
\hline Previous ECG, $\%$ & 84.3 & 77.8 & 81.1 \\
\hline History of arrhythmia, $\%$ & 68.0 & 54.3 & 61.1 \\
\hline Atrial fibrillation/flutter & 54.9 & 51.6 & 53.3 \\
\hline SVT (SNRT, AVNRT, AVRT) & 8.5 & 1.3 & 4.9 \\
\hline Ventricular tachycardia/fibrillation & 5.9 & 1.3 & 3.6 \\
\hline \multicolumn{4}{|l|}{ Medical history, $\%$} \\
\hline Hypertension & 60.8 & 62.8 & 61.8 \\
\hline Coronary artery disease & 32.7 & 32.7 & 32.7 \\
\hline Heart failure & 30.7 & 33.3 & 32.0 \\
\hline Diabetes mellitus & 22.2 & 31.4 & 26.8 \\
\hline Valvular heart disease & 23.5 & 15.0 & 19.3 \\
\hline COPD/asthma & 13.7 & 18.3 & 16.0 \\
\hline Pacemaker/ICD & 16.3 & 15.7 & 16.0 \\
\hline Stroke/TIA & 15.7 & 15.0 & 15.4 \\
\hline Cardiac ablation & 11.8 & 2.0 & 6.9 \\
\hline \multicolumn{4}{|l|}{ Current medications, $\%$} \\
\hline Anti-arrhythmic medication $(N=20: 9: 29)$ & 13.1 & 5.9 & 9.5 \\
\hline Amiodarone & 95.0 & 88.9 & 93.1 \\
\hline Flecainide & 0.0 & 11.1 & 3.4 \\
\hline Propafenone & 5.0 & 0.0 & 3.4 \\
\hline
\end{tabular}


Table 1 (continued)

\begin{tabular}{llll}
\hline Characteristics & $\begin{array}{l}\text { Primary WCT } \\
N=153\end{array}$ & $\begin{array}{l}\text { WCT secondary to } \\
\text { underlying cause } \\
N=153\end{array}$ & $\begin{array}{l}\text { Total } \\
\text { visits } \\
(N=306)\end{array}$ \\
\hline Rate control medication $(N=84: 81: 165)$ & 54.9 & 52.9 & 53.9 \\
Beta-blockers & 92.9 & 88.9 & 90.9 \\
Calcium channel blocker & 7.1 & 9.9 & 8.5 \\
Digoxin & 3.6 & 9.9 & 6.7 \\
Oral anticoagulant & 47.1 & 45.5 & 45.1 \\
Anti-platelet & 32.0 & 22.9 & 27.5 \\
\hline
\end{tabular}

Includes both index and subsequent ED visits within study period

$W C T$ wide complex tachycardia, $S D$ standard deviation, $I C D$ implantable cardioverter defibrillator, $C T A S$ Canadian triage and acuity scale, GCS Glasgow coma scale, $I Q R$ interquartile range, $S B P$ systolic blood pressure, SVT (SNRT, AVNRT, AVRT) supraventricular tachycardia (sinus nodal re-entrant tachycardia, atrioventricular nodal re-entrant tachycardia, atrioventricular re-entrant tachycardia), COPD chronic obstructive pulmonary disease, TIA transient ischemic attack

${ }^{a}$ Indicates correct denominators where data are missing

\section{Results}

We identified 372 potential subjects and after excluding 66, enrolled 306 cases into the study (Online Appendix Fig. 1). This equates to an incidence of 11 cases per month or $0.2 \%$ of ED visits. The patients had mean age 73.9 years, were male $66.0 \%$, had a mean heart rate $131.4 \mathrm{bpm}$ (maximum 227) (Table 1). The most common presenting complaints were palpitations, shortness of breath, and chest pain; $61.1 \%$ had a prior history of arrhythmia. The proportions of primary and secondary WCT were exactly $50.0 \%$ (95\% CI 44.4-55.6\%) each. The secondary cases were more likely to be febrile (9.2\% vs $0.7 \%$ ), to have a Glasgow Coma Scale score $<15$ (38.9\% vs $7.8 \%)$, and to have arrived by ambulance $(62.1 \%$ vs $32.7 \%)$ (Online Appendix Table 1$)$.

The cases with primary WCT were more likely to have an ECG HR $\geq 140$ (47.7\% vs $26.1 \%$ ) (Table 2). Comparing the primary to secondary WCT cases, the ECG rhythms were: $\mathrm{AF}(34.0 \%$ vs $45.8 \%)$, atrial flutter (AFL) $(25.5 \%$ vs $13.1 \%)$, sinus tachycardia $(4.6 \%$ vs $30.1 \%)$, SVT $(16.9 \%$ vs $4.9 \%)$, VT $(11.1 \%$ vs $0 \%)$. Cardiology classified $3.3 \%$ of ECGs as uncertain rhythm.

The primary WCT cases were less likely to require resuscitative measures (12.4\% vs $24.2 \%$ ) but were more likely to receive electrical cardioversion/defibrillation $(41.2 \%$ vs $2.0 \%)$ and rhythm or rate control agents $(52.3 \%$ vs $19.6 \%)$ (Table 3 ). In contrast, the primary WCT cases were much less likely to receive non-cardiac treatments such as IV fluid boluses ( $18.3 \%$ vs $41.8 \%$ ), antibiotics (3.3\% vs $45.8 \%$ ), analgesics $(5.2 \%$ vs $32.0 \%)$, and diuretics $(7.2 \%$ vs $22.2 \%)$. The secondary WCT cases were much more likely to be admitted (73.2\% vs $33.3 \%$ ) and more likely to go to ICU/CCU/monitored unit (58.2 vs $30.0 \%$ ) (Table 4). The secondary WCT cases were more likely to die in the ED (3.9\% vs $0.7 \%)$ and in the subsequent 14 days (9.8\% vs 3.3\%). (See also Online Appendix Table 2).

In $20 \%$ of cases, the ED physicians failed to record their impression of the ECG rhythm (Table 5). They were most accurate versus the post hoc cardiologist interpretation for AF (95.0\%) and VT (88.2\%) and less accurate for AFL (63.5\%) and SVT (68.0\%). Cardiologists classified $7.0 \%$ of these ECGs as uncertain rhythm (Online Appendix Table 3).

In Table 6 and Online Appendix Tables 4 and 5, we see that the ED physicians were accurate in their final clinical diagnosis of both primary (88.9\%) and secondary (88.2\%) cases of WCT compared to that stated in consultation notes or discharge summaries.

We found that the ED physicians provided optimal treatment for $84.3 \%$ of primary WCT cases and for $86.9 \%$ of secondary cases (Table 7). For the primary cases, the most common treatment issues were failure to lower heart rate to $<100 \mathrm{bpm}$ for patients discharged home $(9.1 \%)$, inappropriate drug (3.9\%), not treating VT according to ACLS guidelines (2.6\%), and failure to prescribe oral anticoagulants $(2.0 \%)$. For the secondary cases, the most common treatment issues were failure to lower heart rate to $<100 \mathrm{bpm}$ prior to discharge home (34.4\%), failure to treat the underlying condition (5.9\%), and use of inappropriate drug (1.3\%).

\section{Discussion}

\section{Interpretation}

In this first reported review of WCT management in the $\mathrm{ED}$, we found the overall incidence of WCT to be $0.2 \%$ of patient visits. These WCT cases in the ED were evenly split between primary arrhythmias and tachycardia secondary to medical issues. The secondary cases were more likely to be 
Table 2 Investigations for 306 emergency department patients with rapid heart rate and wide QRS complexes

\begin{tabular}{|c|c|c|c|}
\hline Characteristics & $\begin{array}{l}\text { Primary WCT } \\
N=153\end{array}$ & $\begin{array}{l}\text { WCT secondary to } \\
\text { underlying cause } \\
N=153\end{array}$ & $\begin{array}{l}\text { Total visits } \\
N=306\end{array}$ \\
\hline \multicolumn{4}{|l|}{ Initial ECG Assessment } \\
\hline Heart Rate, bpm, mean & 145.3 & 134.2 & 139.8 \\
\hline Heart rate $\geq 140, \%$ & 47.7 & 26.1 & 36.9 \\
\hline Heart rate $\geq 150, \%$ & 29.4 & 10.5 & 19.9 \\
\hline \multicolumn{4}{|l|}{ Rhythm, \% ${ }^{\mathrm{a}}$} \\
\hline Atrial fibrillation & 34.0 & 45.8 & 39.9 \\
\hline Atrial flutter & 25.5 & 13.1 & 19.3 \\
\hline Sinus tachycardia & $4.6^{\mathrm{b}}$ & 30.1 & 17.3 \\
\hline SVT (SNRT, AVNRT, AVRT) & 16.9 & 4.9 & 10.8 \\
\hline Pre-excited tachycardias & 1.3 & 0.0 & 0.7 \\
\hline Ventricular tachycardia & 11.1 & 0.0 & 5.6 \\
\hline Ventricular paced rhythm & $2.6^{\mathrm{c}}$ & 3.9 & 3.3 \\
\hline Uncertain interpretation & 3.9 & 2.6 & 3.3 \\
\hline \multicolumn{4}{|l|}{ Interval time, ms, mean } \\
\hline PR & 137.2 & 136.5 & 136.7 \\
\hline QRS & 142.9 & 138.2 & 140.6 \\
\hline QTc & 504.4 & 500.9 & 502.6 \\
\hline Bundle branch block, $\%$ & 83.6 & 90.9 & 87.3 \\
\hline \multicolumn{4}{|l|}{ Laboratory values, $\%$} \\
\hline 1st Troponin $>99$ th percentile $^{\mathrm{d}}(N=121: 139: 260)$ & 45.8 & 50.3 & 48.0 \\
\hline 2nd Troponin $>99$ th percentile $(N=44: 41: 85)$ & 25.5 & 17.0 & 21.2 \\
\hline Chest X-ray, \% & 41.2 & 77.1 & 59.2 \\
\hline Pleural effusion & 8.5 & 27.5 & 17.9 \\
\hline Heart failure ${ }^{\mathrm{e}}$ & 4.6 & 20.0 & 11.7 \\
\hline Infiltrate/consolidation/mass & 1.3 & 17.0 & 9.2 \\
\hline Cardiomegaly & 5.8 & 11.1 & 8.5 \\
\hline
\end{tabular}

Includes both index and subsequent ED visits within study period

$W C T$ wide complex tachycardia, $S D$ standard deviation, SVT (SNRT, AVNRT, AVRT) supraventricular tachycardia (sinus nodal re-entrant tachycardia, atrioventricular nodal re-entrant tachycardia, atrioventricular re-entrant tachycardia)

${ }^{a}$ ECG rhythm as determined by the final cardiologist interpretation

${ }^{b}$ Sinus tachycardia included as primary as the cardiac rhythm changed during the course of treatment in the emergency department, requiring treatment as a primary WCT

${ }^{c}$ Ventricular paced rhythm included as primary as the cardiac rhythm changed during the course of treatment in the emergency department, requiring treatment as a primary WCT

${ }^{\mathrm{d}}$ Includes both Troponin $\mathrm{T}$ and Troponin I assays as the laboratory test was changed from Troponin I to Troponin $\mathrm{T}$ during the study period

${ }^{\mathrm{e}}$ Includes indications of pulmonary edema, perihilar edema, Kerley B lines, and vascular redistribution febrile, have a GCS score $<15$, have arrived by ambulance, have an ECG HR $<140$, receive IV fluid boluses and antibiotics, be admitted, and die within 14 days. 3\% of ECG rhythms were interpreted as uncertain diagnosis by cardiologists. The ED physicians interpreted the ECG correctly versus the cardiologist read in $82 \%$ of cases but had difficulty always identifying AFL and SVT. Further, the ED physicians were highly accurate in their final clinical diagnosis of both primary and secondary cases. These physicians provided optimal treatment for the majority of cases, but we did identify opportunities for improvement as discussed below. Differentiating between a primary arrhythmia and secondary tachycardia is essential as the treatments and outcomes are quite different. 
Table 3 Treatment in ED of 306 emergency department patients with rapid heart rate and wide QRS complexes

\begin{tabular}{|c|c|c|c|}
\hline Treatment details (\%) & $\begin{array}{l}\text { Primary WCT } \\
N=153\end{array}$ & $\begin{array}{l}\text { WCT secondary to underly- } \\
\text { ing cause } \\
N=153\end{array}$ & $\begin{array}{l}\text { Total visits } \\
N=306\end{array}$ \\
\hline Resuscitation, \% & 12.4 & 24.2 & 18.3 \\
\hline IV fluid bolus $>250 \mathrm{ml}$ & 11.1 & 20.9 & 16.0 \\
\hline Vasopressors & 3.9 & 11.8 & 7.8 \\
\hline Intubation & 2.6 & 11.8 & 8.8 \\
\hline Bag valve mask & 3.3 & 9.2 & 6.2 \\
\hline Cardiopulmonary resuscitation & 3.3 & 4.6 & 3.9 \\
\hline Duration of CPR, min, mean & 0.7 & 2.0 & 1.3 \\
\hline Electrical cardioversion/defibrillation, $\%(N=63: 3: 66)$ & 41.2 & $2.0^{\mathrm{a}}$ & 21.6 \\
\hline Shocks delivered, median & 1 & 1 & 1 \\
\hline Sedation & 39.2 & 0.0 & 19.6 \\
\hline Synchronized & 39.9 & 0.7 & 20.3 \\
\hline ROSC achieved & 2.6 & 2.0 & 2.3 \\
\hline Did spontaneous breathing resume & 1.3 & 0.7 & 1.0 \\
\hline If ROSC were vasopressors required & 2.0 & 2.0 & 2.0 \\
\hline \multicolumn{4}{|l|}{ Subsequent rhythm, $\%$} \\
\hline Normal sinus rhythm & 37.9 & 0.7 & 19.3 \\
\hline Brady arrhythmia & 0.0 & 0.7 & 0.3 \\
\hline Asystole & 0.7 & 0.0 & 0.3 \\
\hline Other & 0.7 & 0.7 & 0.7 \\
\hline No change & 2.0 & 0.0 & 1.0 \\
\hline Adverse airway events, $\%$ & 14.4 & 0.0 & 13.7 \\
\hline Other non-pharmacological rhythm control, $\%(N=15: 0: 15)$ & 9.8 & 0.0 & 4.9 \\
\hline Vagal manoeuvre & 9.2 & 0.0 & 4.6 \\
\hline Magnet & 0.7 & 0.0 & 0.3 \\
\hline Rhythm or rate control medication given, $\%(N=80: 30: 110)$ & 52.3 & 19.6 & 36.0 \\
\hline Beta blocker $^{\mathrm{b}}$ & 28.1 & 17.0 & 22.5 \\
\hline Amiodarone $^{\mathrm{b}}$ & 19.0 & 3.3 & 11.1 \\
\hline Calcium channel blocker ${ }^{\mathrm{b}}$ & 11.1 & 2.0 & 6.5 \\
\hline Adenosine & 12.4 & 0.0 & 6.2 \\
\hline Procainamide/lidocaine & 8.5 & 0.7 & 4.6 \\
\hline Magnesium & 6.5 & 1.3 & 3.9 \\
\hline Other & 0.0 & 1.3 & 0.7 \\
\hline Adverse reactions to rhythm or rate control medication, $\%$ & 3.9 & 3.3 & 3.6 \\
\hline Non-cardiac treatments, $\%$ & 39.2 & 89.5 & 64.4 \\
\hline IV fluid bolus $>250 \mathrm{ml}$ & 46.7 & 41.8 & 30.1 \\
\hline Antibiotics & 8.3 & 45.8 & 24.5 \\
\hline Analgesics & 13.3 & 32.0 & 18.6 \\
\hline Diuretics & 18.3 & 22.2 & 14.7 \\
\hline Spontaneous conversion to NSR \% & 16.3 & 8.5 & 12.4 \\
\hline
\end{tabular}

$W C T$ wide complex tachycardia, $I V$ Intravenous, $S D$ standard deviation, $I Q R$ interquartile range, $R O S C$ return of spontaneous circulation, $N S R$ normal sinus rhythm

Includes both index and subsequent ED visits within study period

${ }^{a}$ Three cases where defibrillation was required, due to cardiac arrest, during the treatment of a patient with WCT secondary to underlying cause

${ }^{\mathrm{b}}$ Includes IV and PO doses

\section{Previous studies}

While we identified guidelines and review articles discussing management of WCT, we found no studies of WCT prevalence or management in the ED. There are many articles addressing the deficiencies of ECG interpretation 
Table 4 Disposition and follow-up (\%)

\begin{tabular}{|c|c|c|c|}
\hline Disposition details & $\begin{array}{l}\text { Primary WCT } \\
N=153\end{array}$ & $\begin{array}{l}\text { WCT secondary to underly- } \\
\text { ing cause } \\
N=153\end{array}$ & $\begin{array}{l}\text { Total } \\
N=306\end{array}$ \\
\hline Patient discharged by the ED physician, $\%$ & 58.1 & 18.3 & 38.2 \\
\hline \multicolumn{4}{|l|}{ Disposition, $\%$} \\
\hline Discharged home & 64.7 & 20.9 & 42.8 \\
\hline Admitted & 33.3 & 73.2 & 53.3 \\
\hline Monitored area & 16.3 & 34.0 & 25.2 \\
\hline $\mathrm{CCU} / \mathrm{ICU}$ & 13.7 & 24.2 & 19.0 \\
\hline Ward & 3.3 & 15.0 & 9.2 \\
\hline Death in ED & 0.7 & 3.9 & 2.3 \\
\hline Transfer & 1.3 & 2.0 & 1.6 \\
\hline \multicolumn{4}{|l|}{ Admitting service, $\%(N=51: 112: 163)$} \\
\hline Cardiology & 80.4 & 27.7 & 44.2 \\
\hline Medicine & 15.7 & 50.9 & 39.9 \\
\hline Critical care & 3.9 & 16.1 & 12.3 \\
\hline Time to consultant at bedside, hours, median, $(N=65: 123: 188)$ & 4.2 & 4.3 & 4.3 \\
\hline ED length of stay, hours, median & 5.8 & 11.1 & 7.8 \\
\hline Outpatient follow-up recommended, $\%(N=93: 27: 120)$ & 60.8 & 17.7 & 39.2 \\
\hline Cardiology & 80.6 & 44.4 & 72.5 \\
\hline Family medicine & 24.7 & 48.1 & 30.0 \\
\hline Other & 5.4 & 18.5 & 8.3 \\
\hline Death in ED, \% $(N=1: 6: 7)$ & 0.7 & 3.9 & 2.3 \\
\hline Cardiac & 100.0 & 33.3 & 42.9 \\
\hline Other & 0 & 66.6 & 57.0 \\
\hline Return ED visit within 2 weeks, $\%$ & 15.7 & 10.5 & 13.1 \\
\hline Death within 14 days, $\%(N=5: 15: 20)$ & 3.3 & 9.8 & 6.5 \\
\hline Cardiac & 60.0 & 40.0 & 45.0 \\
\hline Other & 40.0 & 60.0 & 55.0 \\
\hline
\end{tabular}

$W C T$ wide complex tachycardia, $E D$ emergency department, $C C U / I C U$ coronary care unit/intensive care unit, IQR interquartile range Includes both index and subsequent ED visits within study period

Table 5 Accuracy of ECG rhythm identification for 234 emergency department patients with rapid heart rate and wide QRS complexes where ED physician recorded their interpretation

\begin{tabular}{lll}
\hline & $\begin{array}{l}\text { Cardiologist inter- } \\
\text { pretation }(N=234) \\
(\%)\end{array}$ & $\begin{array}{l}\text { ED physician } \\
\% \text { agreement }\end{array}$ \\
\hline Atrial fibrillation & $100(42.7)$ & 95.0 \\
Atrial flutter & $52(22.2)$ & 63.5 \\
Sinus tachycardia & $28(12.0)$ & 78.6 \\
SVT (SNRT, AVNRT, AVRT) & $25(11.1)$ & 68.0 \\
Pre-excited tachycardia & $2(0.9)$ & 0 \\
Ventricular tachycardia & $17(7.3)$ & 88.2 \\
Ventricular paced rhythm & $10(4.3)$ & 80.0 \\
Total & $234(100.0)$ & 81.2 \\
\hline
\end{tabular}

$E C G$ electrocardiogram, $E D$ emergency department, SVT (SNRT, $A V N R T, A V R T$ ) supraventricular tachycardia (sinus nodal re-entrant tachycardia, atrioventricular nodal re-entrant tachycardia, atrioventricular re-entrant tachycardia by physicians in general, but none dealing with WCT [16]. Many articles focus on identifying acute myocardial infarction or the accuracy of machine interpretations.

\section{Limitations}

As this was a health records review, some information was occasionally missing or incomplete in the clinical record. For example, ED physicians failed to indicate their ECG interpretation in about $20 \%$ of cases. Overall, however, there were few missing data. This study was conducted at only one ED site over a limited period of time. Regardless, the ED was staffed by 95 well trained attending physicians and is likely representative of most academic EDs in the U.S. and Canada. While we only reviewed 28 months of cases, the sample size of 306 cases far exceeds anything previously reported. Our decision to only study patients with heart rate $\geq 120 \mathrm{bpm}$ was arbitrary but gave us a higher yield of 
Table 6 Accuracy of determination of clinical diagnosis for 306 emergency department patients with rapid heart rate and wide QRS complexes

\begin{tabular}{|c|c|c|}
\hline Final diagnosis & $\begin{array}{l}\text { Final diagnosis according to consultant or } \\
\text { discharge summary }(\%)(N=306)\end{array}$ & $\begin{array}{l}\text { ED physician } \% \\
\text { agreement with final } \\
\text { diagnosis }\end{array}$ \\
\hline Primary arrythmia & $153(100.0)$ & $98.1^{\mathrm{a}}$ \\
\hline Acute atrial fibrillation & $69(45.1)$ & 91.3 \\
\hline Acute atrial flutter & $34(22.2)$ & 88.2 \\
\hline SVT (SNRT, AVNRT, AVRT) & $20(13.1)$ & 80.0 \\
\hline Pre-excited atrial fibrillation & $2(1.3)$ & 50.0 \\
\hline Ventricular tachycardia & $27(17.6)$ & 96.3 \\
\hline Uncertain primary arrhythmia & $1(0.7)$ & 0.0 \\
\hline Correctly identified arrhythmia for primary WCT & $153(100.0)$ & 88.9 \\
\hline Secondary to an underlying cause & $153(100.0)$ & $96.1^{\mathrm{a}}$ \\
\hline Infection & $49(32.0)$ & 93.9 \\
\hline Heart failure/cardiomyopathy & $35(22.9)$ & 80.0 \\
\hline Acute coronary syndrome & $14(9.2)$ & 78.6 \\
\hline Cardiac arrest & $10(6.5)$ & 100.0 \\
\hline Painful condition & $9(5.9)$ & 77.8 \\
\hline Anxiety/dementia/substance use issue & $7(4.6)$ & 100.0 \\
\hline Cerebrovascular/thromboembolism & $6(3.9)$ & 100.0 \\
\hline Respiratory condition ${ }^{\mathrm{b}}$ & $5(3.3)$ & 80.0 \\
\hline Bleeding/hypovolemia & $5(3.3)$ & 100.0 \\
\hline Acute kidney injury/metabolic disorder/electrolyte abnormality & $5(3.3)$ & 100.0 \\
\hline Other $^{\mathrm{c}}$ & $8(5.2)$ & 75.0 \\
\hline Correctly identified diagnosis for WCT secondary to underlying cause & $153(100.0)$ & 88.2 \\
\hline
\end{tabular}

SVT (SNRT, AVNRT, AVRT), supraventricular tachycardia (sinus nodal re-entrant tachycardia, atrioventricular nodal re-entrant tachycardia, atrioventricular re-entrant tachycardia;

${ }^{\text {a }}$ Percentage correctly identify as primary or secondary cases

${ }^{\mathrm{b}}$ Lung infection, COPD, asthma

${ }^{\mathrm{c}}$ Other secondary causes include medication non-compliance, seizure, autonomic dysreflexia, stimulants, pericarditis, and pancreatitis

seriously ill patients. Our appropriateness of treatment evaluations may also appear to have been arbitrary but are based on current guidelines and significant clinical experience of the emergency medicine and cardiology investigators.

\section{Implications}

While ED physicians performed very well, they should consider opportunities for improvement. The physicians overcalled AFL on ECG with $1 / 3$ of cases actually being AF, SVT, or sinus tachycardia. Similarly, they overcalled SVT with $40 \%$ of cases being AF, AFL, or uncertain. Training and continuing professional development may highlight these challenges. We identified opportunities for improved management in $15 \%$ of cases, with the most common omission being failure to adequately reduce the heart rate for both the primary and secondary patients discharged home from the ED. The next most common omission for the secondary cases was failure to treat the underlying cause. Physicians should be mindful of other potential issues such as inappropriate choice of drug, failure to cardiovert or prescribe anticoagulation for acute $\mathrm{AF}$, according to current guidelines.

ED physicians are highly trained experts in dealing with unstable patients requiring immediate resuscitation [7]. Residents and staff physicians alike should be aware of current guidelines for dealing with stable WCT patients $[8,11]$. While there are multiple approaches to identifying VT from sinus tachycardia with aberrant conduction, the most prudent course is to assume VT until proven otherwise. When the diagnosis is uncertain in unstable patients, proceed to immediate electrical cardioversion. In stable patients with uncertain diagnosis, then guidelines suggest a trial of vagal manoeuvres, adenosine, and IV procainamide. IV amiodarone may be considered but verapamil is not recommended when the diagnosis is uncertain in WCT. Finally, if the prior measures are unsuccessful, then electrical cardioversion is indicated.

Another consideration is that a subsequent cardiac electrophysiology consultation may be assisted if ED physicians more often used adenosine to unmask certain arrhythmias that may be difficult to induce in the laboratory but could 
Table 7 Appropriateness of treatment of 306 emergency department patients with rapid heart rate and wide QRS complexes

\begin{tabular}{llll}
\hline Treatments (\%) & $\begin{array}{l}\text { Primary WCT } \\
N=153\end{array}$ & $\begin{array}{l}\text { WCT secondary to } \\
\text { underlying cause } \\
N=153\end{array}$ & $\begin{array}{l}\text { Total } \\
N=306\end{array}$ \\
\hline $\begin{array}{l}\text { Optimal treatment (\%) } \\
\text { Suboptimal treatment }(\%)^{\mathrm{a}}\end{array}$ & $129(84.3)$ & $133(86.9)$ & $262(85.6)$ \\
$\quad \begin{array}{l}24(15.6) \\
\text { Failure to lower HR to }<100 \mathrm{bpm} \text { if dis- }\end{array}$ & $9(9.1)$ & $20(13.1)$ & $20(14.4)$ \\
$\quad$ charged home $(N=99: 32: 131)$ & & $11(34.4)$ & $9(2.9)$ \\
Inappropriate drug & $6(3.9)^{\mathrm{b}}$ & $2(1.3)^{\mathrm{c}}$ & $9(2.9)$ \\
Failure to treat underlying cause & $\mathrm{NA}$ & $9(5.9)$ & $4(1.3)$ \\
ACLS guidelines not followed for VT & $4(2.6)^{\mathrm{d}}$ & 0 & $4(1.3)$ \\
Failure to cardiovert AF/AFL & $4(2.6)$ & 0 & $3(1.0)$ \\
Oral anticoagulants not prescribed & $3(2.0)$ & 0 & $2(0.7)$ \\
Inappropriate cardioversion attempt & $1(0.7)$ & $1(0.7)$ & 0 \\
Inappropriate dose & 0 & 0 & \\
\hline
\end{tabular}

$W C T$ wide complex tachycardia, $b p m$ beats per minute, $H R$ heart rate, $E D$ emergency department, $V T$ ventricular tachycardia, $A F / A F L$ atrial fibrillation/atrial flutter

${ }^{\text {a }}$ Some cases have more than one suboptimal treatment concern

${ }^{b}$ Cases include: one inappropriate use of metoprolol as first-line treatment for ventricular tachycardia, one attempted but unsuccessful cardioversion with amiodarone for a patient with primary atrial fibrillation and a high risk of thrombosis, one use of an AV nodal blocking medication in a patient having ventricular preexcitation (Wolff-Parkinson-White syndrome), one case where a beta blocker was administer to a patient who presented in heart failure resulting in exacerbation of heart failure, two cases where amiodarone was selected as a medication for cardioversion of atrial fibrillation

${ }^{c}$ Cases include one attempted but unsuccessful cardioversion with procainamide for a patient with elevated risk of thrombosis and atrial fibrillation secondary to sepsis, one attempt to treat atrial fibrillation secondary to sepsis as a primary arrhythmia using metoprolol

${ }^{\mathrm{d}}$ Four cases where neither cardioversion nor antiarrhythmic medications were initiated for a patient with ventricular tachycardia

${ }^{\mathrm{e}}$ Cardioversion indicated for AF/AFL according to the 2018 CAEP AF Best Practices Checklist be amenable to curative catheter ablation therapy. This is particularly the case for atrial flutter and some non-ischemic ventricular tachycardias. Marill and colleagues from Harvard examined 197 patients treated in the ED for regular wide complex tachycardia and found adenosine to be useful and safe as a diagnostic and therapeutic agent [17].

Future studies might evaluate the impact of interventions to improve ECG recognition and management in WCT.

\section{Conclusions}

We found that WCT cases in the ED were evenly split between primary arrhythmias and tachycardia secondary to medical issues. The secondary cases were more likely to require admission and to die. ED physicians interpreted the ECG correctly versus the cardiology read in $80 \%$ of cases but often overcalled AFL and SVT. The ED physicians, however, were highly accurate in their final clinical diagnosis of both primary and secondary cases. These physicians provided optimal management for the majority of cases, but there were some omissions in care. These findings suggest ED physicians are excellent at managing WCT but that there are opportunities to improve ECG interpretation and treatment of WCT.

Supplementary Information The online version contains supplementary material available at https://doi.org/10.1007/s43678-021-00243-3.

Acknowledgements We gratefully acknowledge the invaluable assistance of the following individuals: Angela Marcantonio and Carolyne Kennedy of the Ottawa Hospital Research Institute (Ottawa, Ontario).

Funding This study was funded by the University of Ottawa Faculty of Medicine through a Mach-Gaensslen Foundation of Canada Award. The funding source had no involvement in the study design, collection, analysis, or interpretation of the data.

\section{Declarations}

Conflict of interest None.

\section{References}

1. Brady WJ, Mattu A, Tabas J, et al. The differential diagnosis of wide QRS complex tachycardia. Am J Emerg Med. 
2017;35(10):1525-9. https://doi.org/10.1016/j.ajem.2017.07.056 (published Online First: 2017/07/25).

2. deSouza IS, Peterson AC, Marill KA. Differentiating types of wide-complex tachycardia to determine appropriate treatment in the emergency department. Emerg Med Pract. 2015;17(7):1-22 (published Online First: 2015/08/27).

3. Garmel GM. Wide complex tachycardias: understanding this complex condition: part 1-epidemiology and electrophysiology. West J Emerg Med. 2008;9(1):28-39 (published Online First: 2008/01/01).

4. Vereckei A. Current algorithms for the diagnosis of wide QRS complex tachycardias. Curr Cardiol Rev. 2014;10(3):262-76. https://doi.org/10.2174/1573403x10666140514103309 (published Online First: 2014/05/16).

5. Chen Q, Xu J, Gianni C, et al. Simple electrocardiographic criteria for rapid identification of wide QRS complex tachycardia: the new limb lead algorithm. Heart Rhythm. 2020;17(3):431-8. https:// doi.org/10.1016/j.hrthm.2019.09.021 (published Online First: 2019/09/24).

6. Littmann L, Olson EG, Gibbs MA. Initial evaluation and management of wide-complex tachycardia: A simplified and practical approach. Am J Emerg Med. 2019;37(7):1340-5. https:// doi.org/10.1016/j.ajem.2019.04.027 (published Online First: 2019/04/28).

7. Panchal AR, Bartos JA, Cabañas JG, et al. Part 3: adult basic and advanced life support: 2020 American Heart Association Guidelines for Cardiopulmonary Resuscitation and Emergency Cardiovascular Care. Circulation. 2020;142(16_suppl_2):S366s468. https://doi.org/10.1161/cir.0000000000000916.

8. Brugada J, Katritsis DG, Arbelo E, et al. 2019 ESC Guidelines for the management of patients with supraventricular tachycardiaThe Task Force for the management of patients with supraventricular tachycardia of the European Society of Cardiology (ESC). Eur Heart J. 2020;41(5):655-720. https://doi.org/10.1093/eurheartj/ ehz467 (published Online First: 2019/09/11).
9. Garmel GM. Wide complex tachycardias: understanding this complex condition part 2-management, miscellaneous causes, and pitfalls. West J Emerg Med. 2008;9(2):97-103.

10. Network E. Reporting Guidelines. United Kingdom.

11. Deyell MW, AbdelWahab A, Angaran P, et al. 2020 Canadian Cardiovascular Society/Canadian Heart Rhythm Society Position Statement on the management of ventricular tachycardia and fibrillation in patients with structural heart disease. Can J Cardiol. 2020;36(6):822-36. https://doi.org/10.1016/j.cjca.2020.04.004 (published Online First: 2020/06/17).

12. Andrade JG, Aguilar M, Atzema C, et al. The 2020 Canadian Cardiovascular Society/Canadian Heart Rhythm Society Comprehensive Guidelines for the Management of Atrial Fibrillation. Can J Cardiol. 2020;36(12):1847-948. https://doi.org/10.1016/j.cjca. 2020.09.001 (published Online First: 2020/11/17).

13. Stiell IG, de Wit K, Scheuermeyer FX, et al. CAEP acute atrial fibrillation/flutter best practices checklist. CJEM. 2021. https:// doi.org/10.1007/s43678-021-00167-y (published Online First: 2021/08/13).

14. Stiell IG, Scheuermeyer FX, Vadeboncoeur A, et al. CAEP acute atrial fibrillation/flutter best practices checklist. Can J Emerg Med. 2018;20(3):334-42.

15. Macle L, Cairns J, Leblanc K, et al. 2016 focused update of the Canadian Cardiovascular Society Guidelines for the Management of Atrial Fibrillation. Can J Cardiol. 2016;32(10):1170-85. https://doi.org/10.1016/j.cjca.2016.07.591.

16. Cook DA, Oh SY, Pusic MV. Accuracy of physicians' electrocardiogram interpretations: a systematic review and meta-analysis. JAMA Intern Med. 2020;180(11):1-11. https://doi.org/10.1001/ jamainternmed.2020.3989 (published Online First: 2020/09/29).

17. Marill KA, Wolfram S, Desouza IS, et al. Adenosine for widecomplex tachycardia: efficacy and safety. Crit Care Med. 2009;37(9):2512-8. https://doi.org/10.1097/CCM.0b013e3181 a93661 (published Online First: 2009/07/23). 